\title{
Pancreatic Enzymes Decreased, CTCAE
}

National Cancer Institute

\section{Source}

National Cancer Institute. Pancreatic Enzymes Decreased, CTCAE. NCI Thesaurus. Code C143731.

A finding based on laboratory test results that indicate an decrease in levels of pancreatic enzymes in a biological specimen. 